\title{
Oral mucosal lesions prevalent in ANC women in Nagpur population
}

\author{
Dr. Apeksha S. Dhole \\ (Department of Oral Medicine \& Radiology, V.S.P.M. Dental College and Research Centre, Nagpur/ Nagpur \\ University, India)
}

\begin{abstract}
Pregnancy is a special state where major physiological and hormonal changes occur. Temporary adaptive changes occur in the body in general as well in oral cavity as the result of increased production of estrogen, progesterone and relaxin.

Thus the present study is designed to assess the prevalence of number, type and site of oral mucosal lesion in pregnant women and their association with trimester and parity of pregnancy.
\end{abstract}

Keywords: oral mucosa, prevalence, pregnancy, physiologic, parity.

\section{Introduction}

Pregnancy is a dynamic state evidenced by several transient changes in mother's body and the oral cavity is no exception. The storm of hormones i.e. oestrogen by ten folds and progesterone by 30 folds and foetal growth induce several systemic as well as local physiologic and physical changes in pregnant woman.

Oral mucous membrane is an excellent indicator of the constitutional state of the patient. The international literature abounds with epidemiological studies of oral lesions, although very few studies offer information on the oral lesions characterizing pregnancy.[1]

The present study was planned to focus the oral lesions derived from actual pregnancy or attributable to the circumstances associated with this special physiological state and will allow us for early detection and management of such alterations.

After approval from ethical committee the study was planned with aim as to study the prevalence of oral mucosal lesions in ANC women attending ANC clinic of tertiary care hospital. The objectives were to study number, site and type of oral mucosal lesions during pregnancy. Also to study the association of oral mucosal lesions with trimester of pregnancy and with parity.

\section{Materials \& method}

The present study is a descriptive cross sectional study in which all ANC women attended to ANC clinic of Lata Mageshakar Hospital, Nagpur from $1^{\text {st }}$ July to $31^{\text {st }}$ August 2013 were considered. All diagnosed ANC women without systemic illness were included in the study. Patient's demographic data \& relevant history noted. Thorough clinical oral examination was carried out under aseptic precautions.[2]

\section{Observations}

Out of 492 ANC women $52.2 \%$ were of second trimester while $22.2 \%$ and $25.6 \%$ were in first and third trimester respectively. $70 \%$ of primigravida and rest was multigravida. Around 79 oral mucosal lesions noted as cheek bite(3.7\%), leukoplakia(3.0\%), RAS(2.8\%), candidiasis $(2.6 \%), \quad \mathrm{BMG}(2.4 \%)$, pyogenic granuloma(2.0\%).All oral mucosal lesions were prevalent during first pregnancy. Cheek bite, RAS, BMG and leukoplakia observed in second trimester. During third trimester candidiasis and pyogenic granuloma were more prevalent. No association found between oral mucosal lesions and trimester (chi sq:0.036, $\mathrm{p}=0.986$ ) and also with no. of pregnancy(chi sq:0.484,p=0.785). No association between oral mucosal lesions and age of patient noted.

\section{Discussion}

Cheek bite is a chronic irritation or injury to the buccal mucosa and present as white keratotic lesion. Literature suggests the significant prevalence in pregnant women. [1] In present study increased incidence was found but not significant. It might be the vomiting, leading to erosion of teeth and then the further changes as many studies support this concept. Anxiety and stress may induce cheek bite habit. [1] Hemalata VT et .al. noted erosion of enamel leading to cheek bite. [3]

RAS though in pregnant patients was observed $(2.8 \%)$ but its prevalence is not significant. [1,4] Rather they noted traumatic lesions and irritative keratosis. Traumatic lesions (4.3\%), irritative keratosis (3.23\%) were found predominantly in pregnant compared to normal.[5] 
BMG was found prevalent (36.8\%) in pregnant patient during second trimester. (Ghalyani et. al.; Laine MA et. al.). [5,6] In present study cases reported during first pregnancy and second trimester. Many females were unaware of the condition. Few of them noted but did not consulted to oral physician as lesions were asymptomatic.

Candidiasis was significantly (15\%) present in pregnant women [1]. During pregnancy it is known that the level of yeasts increases in saliva. The $\mathrm{pH}$ and buffer effct values of saliva have been found to decrease during pregnancy and thus increased candida infection during pregnancy. [7]

Leuloplakia was not seen in any of the previous studies. In present study around $15 \%$ patients noted. Those who had lesion gave positive history of tobacco chewing or keeping at particular site. Most of them started habit as to relieve anxiety or vomiting and GIT upset.

Pyogenic granuloma had prevalence of 3-5\%. [5,8] Increased angiogenesis caused by sex hormones, coupled with local factor is believed to be cause of pyogenic granuloma. It is found prevalent around $3.5 \%$ in present study.

\section{Conclusion}

A gestational woman requires various levels of support throughout this time, such as medical \& dental monitoring, intervention, preventive care and physical and emotional assistance. Assessment and prevention of oral lesions is possible when we know the lesions frequently associated.

\section{Reference}

[1]. Sarifakioglu E, Gundus C et. al. Oral mucosa manifestations in 100 pregnant versus non-pregnant patients: an epidemiological observational study. European Journal of dermatology, vol.16, No.6, 674-4 Nov- Dec 2006.

[2]. Zain RB, Razak IA et al Training examiners for a national epidemiological survey of oral mucosa lesions. Int Dent J 1996; 46: 53642.

[3]. Hemalatha VT, Manigandan J et al, Dental considerations in pregnancy - a critical review on the oral care. J clin diagn res 2013 may; 7(5): 948-953.

[4]. Diaz- Guzman LM et al . Lesions of the oral mucosa and disease behaviour in pregnant patients. Med oral pathol oral cir bucal 2004;9:430-7.

[5]. Laine MA et. al. Effects of pregnancy on dental health. Acta odontol scand 2002; 60: 257-64

[6]. Neville BW, Damm DD, Allen CM et al. Oral and maxillofacial pathology, $2^{\text {nd }}$ Edn Philadelphia: WB Saunders 2002.

[7]. Mumcu G et al Prevalence and distribution of oral lesions: a cross sectional study in Turkey. Oral diseases 2005; 11: 81-7.

[8]. Fatahzadeh M, Kano G et al Epidemiological study of oral mucosal lesions in 1125 community residents. Oral surg oral med oral pathol oral radiol endod 2000: 89:442. 